\title{
CONTROLLED HEMOSTASIS IN THORACIC SURGERY USING DRUGS WITH OXIDIZED CELLULOSE
}

\author{
Petr Habal, Nedal Omran, Jiří Mand'ák, Jiří Šimek, Milan Štětina
}

Charles University in Prague, Faculty of Medicine and University Hospital in Hradec Králové, Czech Republic: Department of Cardiac Surgery

Summary: The authors demonstrate the possibility of improving surgical results by the reduction of perioperative bleeding in thoracic surgery associated with extended resection procedures. We focused on patients in whom the expected perioperative blood loss was greater than $500 \mathrm{ml}$. The first group consisted of patients with lung cancer stage III A after neoadjuvant chemotherapy had been indicated to extend the resection procedure. The second group consisted of patients with chest wall and mediastinum tumors of various etiologies. The third group consisted of patients with post-inflammatory thoracic complications in whom combined decortication and pleurectomy was necessary. By the using the local hemostyptic Traumastem TAF on the basis of oxidized cellulose, it is possible to minimize the perioperative blood loss, thus sparing the blood derivative requirement and enabling surgeons to provide the desired treatment even to high-risk patients.

Key words: Extended lung resection; Thoracic wall tumors; Fibrothorax; Traumastem TAF

\section{Introduction}

Together with the population's increasing age and improvements in oncological therapy there is still an increasing number of patients in whom a large resection procedure is needed to be provided definitive treatment. These large types of procedures were called "extended operations" by Brock in 1948 (2).

One group includes patients indicated for resection procedure after neoadjuvant chemotherapy for lung carcinoma stage III A.

The second group consists of patients with gigantic tumors of the thoracic wall. Only surgical treatment is successful in such cases. The patients are often indicated for surgical procedure in late stages with manifestation of accompanying symptoms from surrounding structure compression.

The third group consists of patients who have had complicated inflammatory diseases of the lungs and the thoracic cavity. For patients such as these, decortication performing and pleurectomy, often with atypical pulmonary resection, is mandatory.

The patients of these groups require a more demanding perioperative course and it is necessary to expect a bigger blood loss from multiple non-surgical sources. It is advantageous to use local hemostyptic agents to eliminate continuous surgically untreatable bleeding.

\section{Materials and Methods}

Between January 2005 and December 2009 we operated on 84 patients from the selected groups (Tab. 1). The first group consists of 51 patients with lung carcinoma of III A stage (Tab. 2). In the second group there are 19 patients with thoracic wall tumors of various etiologies (Tab. 3). The third group includes 14 patients with post-inflammatory fibrotho$\operatorname{rax}$ (Tab. 4).

The first group contains a non-homogeneous set of 32 men and 19 women of average age $54 \pm 14$ years. The nonhomogeneity of this group was caused by the fact that 38

Tab. 1: Set of patients with surgical details

\begin{tabular}{|l|c|c|c|c|c|c|}
\hline Group & M & F & Age & $\begin{array}{c}\text { Peroperative } \\
\text { bleeding (ml) }\end{array}$ & Time of drainage (h) & $\begin{array}{c}\text { Postoperative } \\
\text { bleeding (ml) }\end{array}$ \\
\hline Lung carcinoma & 32 & 19 & $54 \pm 14$ & $830 \pm 210$ & $72 \pm 9$ & $750 \pm 150$ \\
\hline TW Tumors & 12 & 7 & $58 \pm 12$ & $920 \pm 350$ & $72 \pm 12$ & $700 \pm 150$ \\
\hline Fibrothorax & 9 & 5 & $48 \pm 11$ & $600 \pm 150$ & $96 \pm 14$ & $1250 \pm 200$ \\
\hline$\sum$ & 53 & 31 & & & & \\
\hline
\end{tabular}

TW Tumors - thoracic wall tumors, $\mathrm{M}$ - male, $\mathrm{F}-$ female, $\mathrm{ml}$ - milliliter, $\mathrm{h}$ - hour 
Tab. 2: Group of 51 operated patients in stage III A for lung carcinoma

\begin{tabular}{|l|c|c|}
\hline Performance & Number & Death rate \\
\hline Pneumonectomy by Allison & 24 & 2 \\
\hline $\begin{array}{l}\text { Pneumonectomy + part of left } \\
\text { atrium resection }\end{array}$ & 8 & 0 \\
\hline $\begin{array}{l}\text { Lobectomy + part of thoracic } \\
\text { wall resection }\end{array}$ & 9 & 0 \\
\hline $\begin{array}{l}\text { Lobectomy + part } \\
\text { of diaphragm resection }\end{array}$ & 9 & 0 \\
\hline $\begin{array}{l}\text { Pneumonectomy + part } \\
\text { of superior vena cava }\end{array}$ & 1 & 1 \\
\hline Total & $\mathbf{5 1}$ & $\mathbf{3}$ \\
\hline
\end{tabular}

Tab. 3: Group of 19 patients with thoracic wall tumors

\begin{tabular}{|l|c|c|}
\hline Performance & Number & Death rate \\
\hline Resection < than 3 ribs & 7 & 0 \\
\hline Resection > than 3 ribs & 4 & 0 \\
\hline Sternum partial resection & 2 & 0 \\
\hline Resection of ribs + lobectomy & 2 & 0 \\
\hline Resection of ribs + diaphragm & 2 & 0 \\
\hline $\begin{array}{l}\text { Resection of ribs } \\
\text { + vertebrae bodies }\end{array}$ & 2 & 1 \\
\hline Total & $\mathbf{1 9}$ & $\mathbf{1}$ \\
\hline
\end{tabular}

Tab. 4: Group of 14 patients with post-inflammatory fibrothorax

\begin{tabular}{|l|c|c|}
\hline Performance & Number & Death rate \\
\hline Decortication & 3 & 0 \\
\hline Decortication + pleurectomy & 7 & 0 \\
\hline $\begin{array}{l}\text { Decortication + pleurectomy } \\
\text { + atypical lung resection }\end{array}$ & 2 & 0 \\
\hline $\begin{array}{l}\text { Decortication + pleurectomy } \\
\text { + ribs resection }\end{array}$ & 2 & 0 \\
\hline Total & $\mathbf{1 4}$ & $\mathbf{0}$ \\
\hline
\end{tabular}

patients had already undergone neoadjuvant chemotherapy, while the rest of them had undergone a surgical procedure without prior neoadjuvant therapy. The unifying element was the oncological classification by TNM criteria, where the patients were classified as III A stage. During extended surgical procedures the resection is extended to the surrounding tissues (Fig. 1).

The second group is a group of patients with thoracic wall tumors consisting of a non-homogeneous group of 12 men and 7 women of average age $58 \pm 12$ years. The vast majority of these tumors were sarcomas and metastatic ribs affection. In two cases there was a peripheral neuroepithelial tumor; in one case there was a rare benignant fibrous dysplasia of the ribs and thoracic vertebral bodies. In all patients it

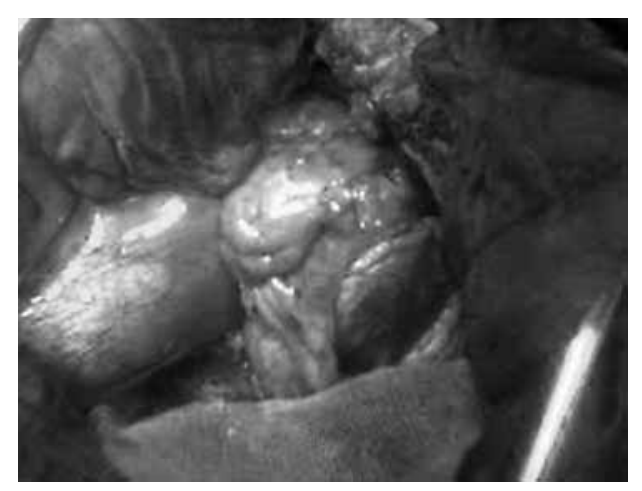

Fig. 1: Pericardium replacement with Traumastem TAF reticulum after lung resection

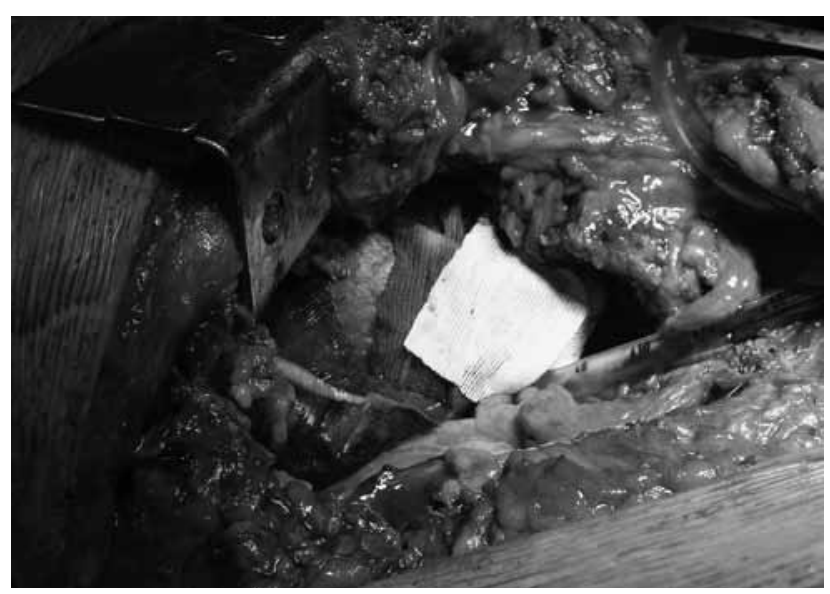

Fig. 2: Use of Traumastem TAF during plastic surgery of thoracic wall

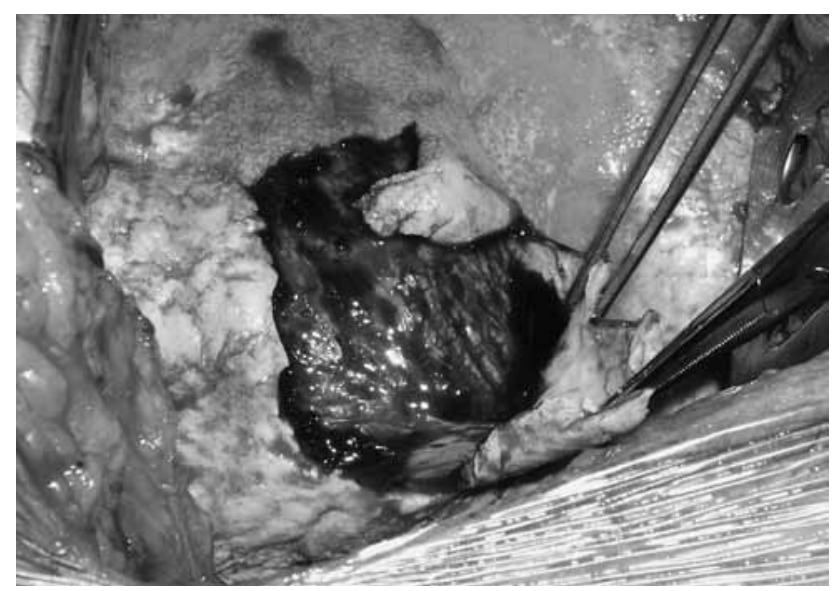

Fig. 3: Decortication of pulmonary surface in fibrothorax treatment

was necessary to perform variously large resections of the thoracic wall with consequent plastic surgery.

In the third group 14 patients were operated on in the monitored period; 9 men and 5 women in various stages of fibrothorax development with an average age of $48 \pm 11$ year. 
The surgical procedure in all cases consisted of pleurectomy of the parietal pleura and decortication of the visceral pleura. The procedures were often accompanied with atypical resection of the pathologically affected pulmonary tissue. After such procedures we cannot avoid creation of a large wound area after the removal of the thickened or calcified pleura from the pulmonary parenchyma surface itself and from the inner area of the chest wall (Fig. 3).

\section{Results}

As a criterion for greater perioperative blood loss, blood loss greater than $500 \mathrm{ml}$ was determined.

In the first group the average perioperative blood loss was $830 \mathrm{ml} \pm 210 \mathrm{ml}$. The dominant sources of bleeding were from the pulmonary tissue during pulmonary resection procedures and from the chest wall during the extrapleural approach to the pulmonary peduncle in the obliterated pleural cavity. Both mentioned bleeding sources are not surgically well controllable because they have a rich vasculature supply. These sources could be a persistent source of bleeding in the postoperative period. It is possible to reduce the bleeding by applying various types of hemostyptic agents, which in our study was Traumastem TAF. By the local application of this agent the average blood loss through the chest tube was $750 \pm 150 \mathrm{ml}$ over a period of $72 \pm 9$ hours.

In the second group perioperative blood loss was around $920 \pm 350 \mathrm{ml}$ during $72 \pm 9$ hours. We assume that such a low blood loss through the chest tube during the postoperative period was influenced by the use of local hemostyptic Traumastem TAF, which covers the whole resected wound area of the chest wall and adjacent the pulmonary tissue (Fig. 2).

Perioperative blood loss in the third group was $600 \pm 150$ $\mathrm{ml}$. Post-operative loss, however, (mostly by two inserted chest tubes) was $1250 \pm 200 \mathrm{ml}$, with an average time of chest tube insertion of $96 \pm 14$ hours. Also, in this group we applied Traumastem TAF directly to the inner area of thoracic wall, assuming that after pulmonary parenchyma

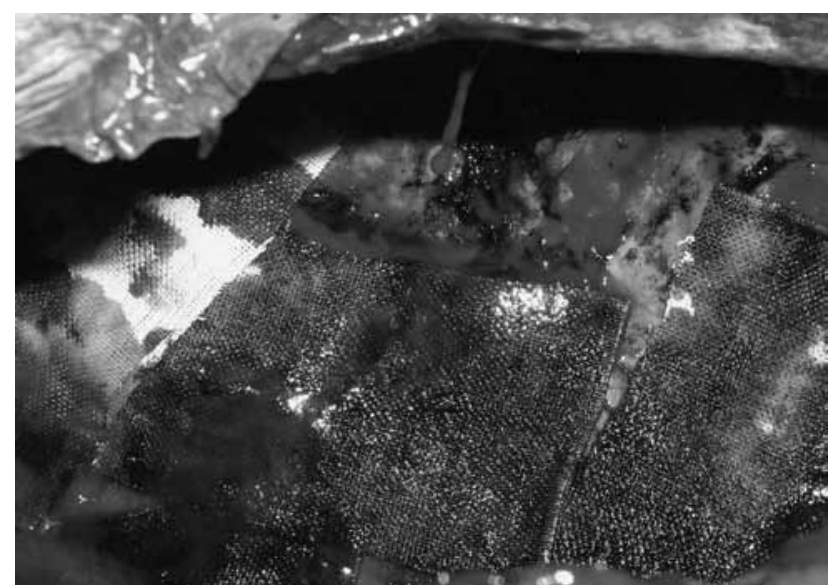

Fig. 4: Haemostasis of decorticated pulmonary surface by using Traumastem TAF expansion the tight adhesion of the pulmonary tissue with the thoracic wall will emerge with disappearance of pleural space (Fig. 4).

\section{Discussion}

Elective surgical procedures in thoracic surgery have been moving toward polymorbid patients. In the first group of patients with an advanced stage of tumor or patients after neoadjuvant chemotherapy, surgical procedures are often accompanied with various complications (16). After neoadjuvant chemotherapy, many infectious complications occur. Decreased immunity may participate in these complications. There is also a higher mortality rate associated with these operations, nearing 17\% (12). The incidence of bronchopleural fistulas after resection pulmonary procedures in patients without chemotherapy is around $1 \%$, whereas in patients who have had chemotherapy it is about $4 \%$ (1). Bleeding control during surgical procedures with the elimination of blood derivative requirements has a positive impact on patient outcomes (14). In the postoperative period, blood loss through the chest tube does not only consist of blood. It is necessary to emphasize that it is a total loss of blood, pleural fluid hyperproduction and also lymphatic fluid loss after performing mediastinal lymphadenectomy (7). We can successfully eliminate this lymphorrhea by apply local hemostyptic on the basis of oxidized cellulose on the paratracheal space area.

Many patients from the second group with giant tumors of the thoracic wall presented with neurological dysfunction caused by spinal cord compression (6).

In some cases it is necessary to perform an initial laminectomy. Radical removal of the tumor and a plastic of the thoracic wall could be provided in the second period. In such cases radical resection procedures should be a priority in view of the fact that definitive histological diagnosis from bioptic examination prior to the operation procedure is not always certain (11). For example, in fibrous dysplasia, a determination of the definitive histological diagnosis is sometimes misleading because the dysplasia can be morphologically similar to sarcoma (13). It is mostly a benignant disease; a malignant transformation occurs in less than $1 \%$ of all known cases (9). Due to the long-term growth and monstrous size of the tumor, compression of the surrounding structures is risky. As an example, cases of thoracic outlet syndrome occurrence with affection of the first rib are described (6). In some cases of peripheral malignant lung tumors we see a spreading to the thoracic wall or to the diaphragm. This type of tumor growth is seen in about $8 \%$ of patients. Even if it affects soft parts of the thoracic wall, compressing ribs or thoracic bone, the mediastinal lymphatic system is not affected by this type of tumor spreading (9). The prognosis for operated patients with resection to the macroscopically healthy tissue is therefore good $(5,8)$. Sometimes during reconstruction of the thoracic wall or diaphragm we do not avoid the use of local hemostyptics to reduce bleeding. The use of biologically degradable materials on the basis of oxi- 
dized cellulose is also suitable since patients often undergo post-operative radiotherapy, where a use of extraneous material complicates further treatment (10). The utilization of antibacterial properties of Traumastem TAF in these cases has a favorable effect on operative wound healing.

In the clinical practice we can find another local haemostyptics such as TachoSil ${ }$, where two active substances, human fibrinogen and human thrombin, are coated onto an equine collagen. This is used preferentially to stop the air leak from the resected pulmonary tissue (4). The use of the local hemostyptics on the basis of polyethylenglycol did not prove efficient enough in our practice.

Fibrous changes in the pleural cavity after inflammatory processes of various etiologies can significantly increase patient morbidity. Progression of respiratory insufficiency due to pulmonary tissue retraction may occur. Such a process can precipitate right heart failure, which in turn can worsen the patient's prognosis. During decortication of the thickened visceral pleura and pleurectomy of the parietal pleura we do not avoid local bleeding from pulmonary tissue surface and from the inner area of the thoracic wall (3). In spite of a well-treated primary cause, mainly thoracic empyema, the number of post-inflammatory complications is on the rise. The spectrum of patients moves to a higher age category associated with a high incidence of comorbidites. Therefore, the effort to reduce blood derivative requirements by using local hemostyptics can play an important role.

\section{Conclusion}

Thoracic surgery, as other surgical fields, has been brought face to face with serious disorders. The surgeon (often as the last step on treatment pyramid), although aware of postoperative complications, cannot reject these serious disorders. We routinely operate under an antibiotic screen of protected coagulum in order to avoid infectious complications, thus saving therapeutic administration of antibiotics in the early post-operative period. There is also an effort to control blood loss and thus reduce the necessity of blood transfers. The methods for saving blood transfers are various. The accepted method of hemodilution as well as advantages of autotransfusion can be used only in a limited group of patients presented here (14). Neither methods of blood recuperation or use of cell-savers are suitable in these cases. It seems that the only method of choice is the use of local hemostyptics. The hemostyptic agent on the basis of oxidized cellulose Traumastem TAF has effective hemostatic properties. It is able to stop the bleeding within 2-6 minutes. The antibacterial effect is reached due to the $\mathrm{pH}$ decrease in the wound with cellulose biodegradation. This mechanism has an effect against a wide spectrum of grampositive and gram-negative bacteria. Traumastem TAF has the ability to accelerate biochemical processes and therefore significantly influences the healing process. Thanks to its properties, it surpasses material used in the past at economically incomparable levels. Finally, we declare that the use of Traumastem TAF is not in conflict of interest, but rather comes about as a result of our long experience with the favorable effect of its application.

\section{Acknowledgements}

The study is supported by the Research Intention MZO 00179906.

\section{References}

1. Asamura H. Bronchopleural fistulas associated with lung cancer operations Univariate and multivariate analysis of risk factors, management and outcome. J Thorac Cardiovasc Surg 1992; 104: 1456-1465.

2. Brock R. Long survival after operation for cancer of the lung. Brit J Surg 1975; 62: $1-5$.

3. de Hoyos A, Sundaresan S. Thoracic empyema. Surgical Clinics of North America 2002; 82(3): 643-671.

4. Carbon RT, et al. Fast-track Surgery of Reccurent Pneumothorax in Patients with Cistic Fibrosis-superiority of Minimally invasisve Tissue Management; 7th World Congress on Trauma, Shock, Inflammation and Sepsis. Munich, March 13-17 2007, by Medimond International Proceedings, Bolgna, 15-28.

5. Gonfiotti A, Santini PF, Campanacci D, Innocenti M, et al. Malignant primary chest-wall tumours: techniques of reconstruction and survival Eur J Cardiothorac Surg 2010; 38: 39-45.

6. Karanjia ND, Sayer RE. Thoracic outlet syndrome due to monostatic fibrous dysplasia of the first rib. J R Coll Surg Edinb 1990; 35: 111.

7. Naruke T. Mediastinal lymph node dissection. In: Shields TW. General thoracic surgery. Philadelphia: Lippincott Williams and Wilkins 2000; 1591.

8. Pairolero PC. Extended resections for lung cancer. How far is too far? Eur J of Cardiothor Surg 1999; 16: 48-50.

9. Pairolero PC. Thoracic wall defect surgical management of 205 consecutive patients: Mayo Clin Proc 1986; 61: 557-563.

10. Puma F, Ragusa M, Daddi G. Chest wall stabilization with synthetic reabsorbable material. Ann Thorac Surg 1992; 53: 408-411.

11. Ruggieri P, Sim FH, Bond JR, Unni KK. Malignancies in fibrous dysplasia. Cancer 1994; 73: 1411-1424.

12. Serhan T, Sukru D. Extended resections for primary lung cancer with oncological principles. Interact CardioVasc Thorac Surg 2010; 11: 385-387.

13. Simpson AH, Creasy TS, Williamson DM. Cystic degeneration of fibrous dysplasia masquerading as sarcoma. J Bone Joint Surg (Br) 1989; 71: 434-436.

14. Slipac J. Bezkrevní medicína, Triton, 2008; 23-26.

15. Venuta F, Rendina EA, De Giacomo T. Technique to reduced air leaks after pulmonary lobectomy. Eur J Cardiothorac Surg 1998; 13: 361-364.

16. Yang HX, Hou X, Lin P, Rong TH, Yang H, Fu JH. Survival and risk factors of surgically treated mediastinal invasion T4 non-small cell lung cancer. Ann Thorac Surg 2009; 88: 372-379.

Received: $13 / 10 / 2010$

Accepted in revised form: 24/10/2011

\section{Corresponding author:}

MUDr. Petr Habal, Charles University in Prague, Faculty of Medicine in Hradec Kralove and University Hospital in Hradec Kralove: Department of Cardiac Surgery, Sokolská 581, 50005 Hradec Králové, Czech Republic; e-mail: phabal@seznam.cz 